\title{
An Analysis on the Opportunity of Introducing Blockchain Technology in Education - A Case Study
}

\author{
Petre Lucian Ogrutan
}

\section{Transilvania Univeristy of Brasov, Electronic and Computer department, Politehnicii no.1, Brasov, Romania}

\begin{abstract}
This paper presents the initiative to increase the flexibility of final year student activity and the results obtained. The didactic achievements illustrated by the grades obtained during the last 3 years show higher performance in students who adopted flexible ways to accomplish their academic activity. The students' opinion was determined through applying questionnaires comparing the activity in the classic way and in the flexible way. The conclusions show the opportunity for a flexible way of organizing the activity, while the organizational difficulties justify the need to use Blockchain technology in managing the attendance and the grades obtained by students.
\end{abstract}

Keywords - Engineering Education, Blockchain, Flexible teaching.

\section{Introduction}

The need to use Blockchain technology at the Faculty of Electrical Engineering and Computer Science arose due to the initiation of a pilot project for the flexible organization of disciplines for the elaboration of the diploma thesis. The pilot project was implemented in the academic year 2018-2019 with Applied Electronics students.

This paper briefly presents the Blockchain technology and some of its uses in higher education. The following presents the initiative to increase the flexibility of final year student activity and the results obtained.

DOI: 10.18421/TEM93-19

https://doi.org/10.18421/TEM93-19

Corresponding author: Petre Lucian OGRUTAN,

Transilvania University of Brasov, Romania.

Email: petre.ogrutan@unitbv.ro

Received: 10 July 2020.

Revised: 05 August 2020.

Accepted: 12 August 2020.

Published: 28 August 2020.

(cc)BY-NC-ND(C) 2020 Petre Lucian OGRUTAN; published by UIKTEN. This work is licensed under the Creative Commons Attribution-NonCommercial-NoDerivs 4.0 License.

The article is published with Open Access at www.temjournal.com
Blockchain technology allows the creation of a decentralized environment that is not controlled by any organization. All transactions completed in this environment are public, and they can be consulted in a public ledger [1]. Satoshi Nakamoto first described the structure of the Blockchain in 2008, as well as its use for the cryptocurrency Bitcoin [2]. Blockchain technology was initially used for cryptocurrencies but its advantages have led to a diversity of applications, including higher education.

Blockchain is a database composed of a series of fixed length blocks, ordered in time. Each block contains one or more validated transactions. After a block is checked and completed it is added to the block chain, all blocks are being publicly visible. The process of adding a transaction consists of:

1. Adding the transaction to the block. On average, the blocks contain approximately $1 \mathrm{MBytes}$ of information and have a time stamp;

2. Cryptographic verification of each transaction;

3. Adding the new block after completion at the end of the block row, no transaction in the block can be deleted or modified (immutable).

A detailed description of Blockchain technology is provided by Bambara and Allen in [3]. In 321 pages, the book, published at Mc Graw Hill in 2018, explains the mechanisms used by Blockchain and offers examples of implementations in various fields such as: finance, real estate business, justice, betting, cloud computing, IoT (Internet of Things) etc.

The purpose of the Blockchain is to provide a reliable support that ensures transparency for transactions of any kind (financial, real estate, administrative, legal, etc.) without the centralization imposed by a certain organization. The proposed change of Blockchain technology in the world economy is important, so there are discussions about its future, as it presents both advantages and disadvantages [4], [5].

There are initiatives about using Blockchain technology in education. Universities currently have campuses in various cities or countries, so that the management and certification of student activity, under safe conditions, can be implemented using this 
technology. The paper [6] analyzes the possibility of managing student profiles and certifications obtained through Blockchain. Paper [1] proposes to perform the management of transferable credits ECTS (European Credit Transfer and Accumulation System) using Blockchain technology. The authors developed an implementation based on the opensource Ark Blockchain Platform, which was used in testing the proposed concept. Paper [7] proposes that all certificates in the field of education are to be issued, kept safe and publicly available through Blockchain technology, which ensures these characteristics. The authors have implemented such a system and the results are presented. Paper [8] presents the possible difficulties of the implementations with Blockchain technology and proposes solutions, then discussing the obtained results. A paper trying to envisage the future of universities [9] states that the current certification system will be weakened by Blockchain technology, especially in a complex and diversified system in which universities will outsource certain courses. A reference document published in the European Community is [10], which addresses in a clear and simple way Blockchain technology and its applications in the field of higher education. In its 137 pages, the document provides documented explanations and discusses the ethical and political implications. The work includes a large number of examples.

\section{The Method of Making the Teaching Activity more Flexible}

Collis and Moonen maintain in [11] the need for activities to become flexible in higher education. The paper establishes the activities that can become flexible and states the need to involve instructors and apply new technologies "For flexible learning to be implemented, instructors and learners will probably need to make use of technology." Barnett identifies 15 conditions for ensuring flexibility and considers that flexibility contributes to enhancing quality in higher education [12]. Society is changing faster and faster, and maintaining education at the same rate of adaptation has been noticed since the 2000s. The issue of flexibility arose at that time and the system of transferable credits according to the Bologna principles emerged, which allows students to take courses in other countries. Increasing student mobility and the development of distance learning have also led to increased flexibility [13]. Currently, more and more students are taking a part-time job during their study period. Their main motivation is the financial one; a few are being those who want a specialization in parallel with the didactic activity [14]. The importance of time management is emphasized in [15] "A balance between structured time (e.g. scheduled lectures, seminars and tutorials) and flexible time (e.g. online learning and independent study) is important for student equity within and across programs of study". The authors maintain that many students choose to drop out due to insufficient study time. According to a study [16] many students in the UK choose local universities for financial reasons. "Nearly all work part-time, or in a few cases full-time, whilst studying."

The curriculum of Applied Electronics includes the activity of preparing the diploma thesis during the 2nd semester in form of practical activity, working with the project supervisor. Analyzing the obtained results, the need emerged to introduce a taught subject to provide the basic notions of academic writing, elaboration of documentation, study of the current level of all students. Therefore, the 2 nd semester of the final academic year will include 6 hours per week for 10 weeks in order to accommodate this kind of subject while maintaining the practical activity of 15 hours per week for 4 weeks, guided by the project supervisor. This system has been applied for several years, with good results reflected in the quality of diploma projects. However, some disadvantages were identified, so a pilot project was initiated providing a flexible unfolding of these subjects allowing each student to make the choices considered necessary, in the order established by each student, provided that the total number of activity hours is completed. The teachers involved in this action saved the durations of the students' activities in a public database and graded the results based on the academic performance of students in scheduled exams.

The students with prominent achievements in the process of preparing the diploma thesis were the same who previously participated with scientific presentations in two student conferences, in the presence of representatives from the employing companies. Presenting papers provides adequate training in support of the diploma thesis while contacts with employers are valuable for getting a job after graduation.

\section{The Results of a Survey on Students' Opinion about the Flexible Working Schedule}

A questionnaire was designed to check students' perceptions of the flexible way of working. A first questionnaire was completed by a group of students who carried out the activity in a classic way (20172018) after watching a presentation about a flexible work schedule. In the following academic year (2018-2019) a group of students carried out the activity in the proposed flexible way and completed a questionnaire with similar questions. The aim of this 
scheme was to identify a correspondence between the opinion of the students who carried out the activity in the classic way and who inferred the effects of the flexible way of working and the opinion of the students involved in a flexible activity. The questionnaires were completed at the end of the year after awarding the final grades. The purpose of the questionnaire was to verify the efficiency of the proposed way of working, in order to continue in the same manner over the following academic years.

The questionnaire was anonymous and completion was not mandatory, it was completed by 22 students out of 26 (2017-2018) and 28 students (out of a total of 34 students) (2018-2019). The scale ranged from 1 to 5,1 meaning total disagreement and 5 total agreement.

The questions in the questionnaires given to the students who carried out the activity in a classic way (2017-2018) respectively to those who carried out the activity in a flexible way (2018-2019) are listed below, along with the distribution of answers and the statistical averages.

1. Due to this flexible work schedule I think I could make more progress in preparing the diploma project compared to a classic schedule. (academic year 2017-2018);

1. Due to this flexible development I have made more progress in preparing the diploma project compared to a classic schedule. (academic year 2018-2019).

The distribution of students' answers is given in Figure 1, in blue for classic and in red for flexible work schedules:

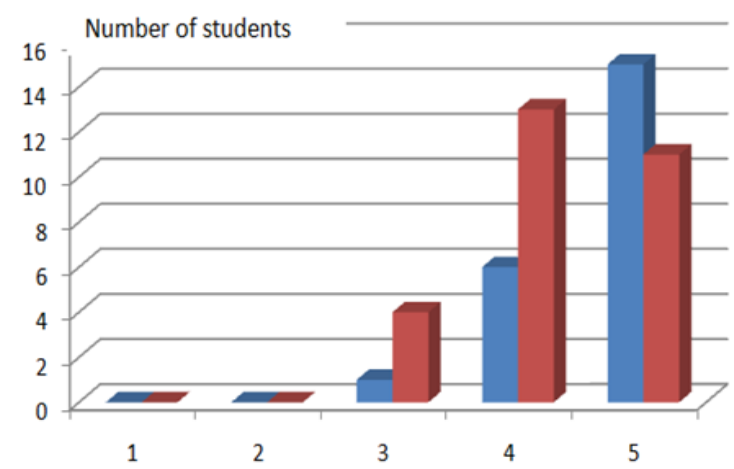

Figure 1. Distribution of answers to question 1, blue classic (academic year 2017-2018), red-flexible work schedule (academic year 2018-2019)

The average of the answers was 4.64 in 2018 and 4.25 in 2019 , the majority of students considering that the flexible work schedule allows for better conditions for preparing the diploma project.
2. Due to the fact that it does not matter when I attend class but only the completion of the required number of hours I will be able to better manage time (academic year 2017-2018);

2. Due to the fact that it did not matter when I attended class but only the completion of the required number of hours I was able to manage my time better. (academic year 2018-2019).

The distribution of the students' answers is given in figure 2, - blue classic, and red flexible work schedule:

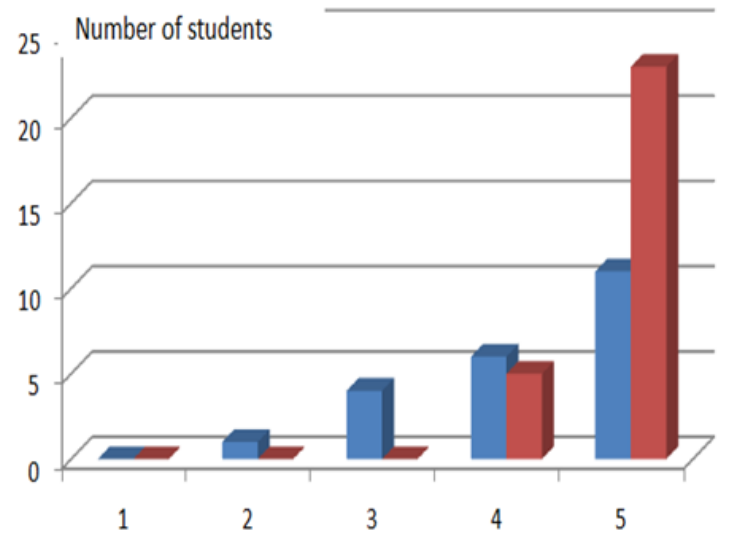

Figure 2. Distribution of answers to question 2, blue classic (academic year 2017-2018), red-flexible work schedule (academic year 2018-2019)

The averages of the answers were 4.23 in 2018 and 4.82 in 2019; most students consider that flexible work schedule allows better time management, a predictable response. The students who chose the flexible classes were more satisfied than those from the previous year for whom the flexible schedule was only a perspective.

3. The advantages of this way of working will be important / 4. The disadvantages of this way of working will be important (academic year 20172018);

3. The advantages of this way of working were important / 4. The disadvantages of this way of working were important. (academic year 20182019).

The distribution of the students' answers is given in Figure 3 , to the question about advantages in blue for classic and in red for flexible work schedule. To the question about disadvantages the used colours are green for classic and yellow for flexible work schedule. 


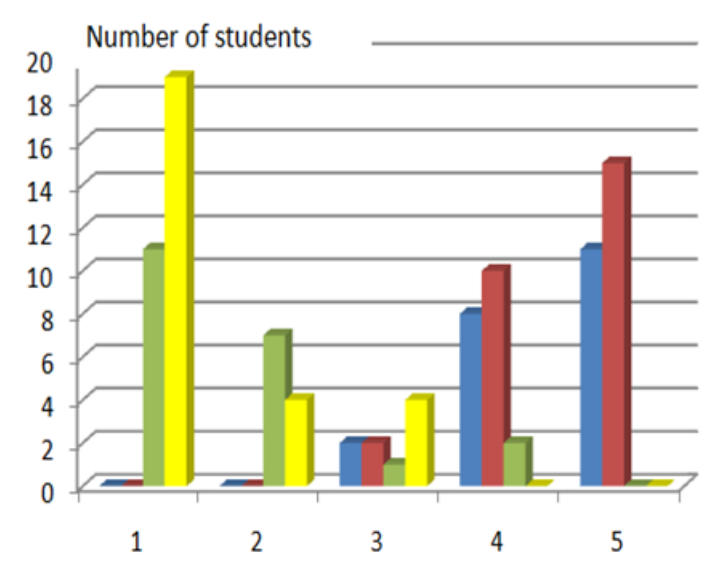

Figure 3. Distribution of answers to question 3 and 4, advantages blue, disadvantages green - classic (academic year 2017-2018), advantages red, disadvantages yellow -

flexible work schedule (academic year 2018-2019)

To the question about advantages the average of the answers was 4.43 in 2018 and 4.32 in 2019, and to the question about disadvantages the average of the answers was 1.71 in 2018 and 1.39 in 2019, which shows that the predicted advantages and disadvantages were correctly appreciated.

5. I consider that the professional results and grades will be better than with a classic work schedule.

5. I consider that the professional results and grades were better than with classic work schedule.

The distribution of the students' answers is given in figure 4 , in blue for classic and red for flexible work schedule:

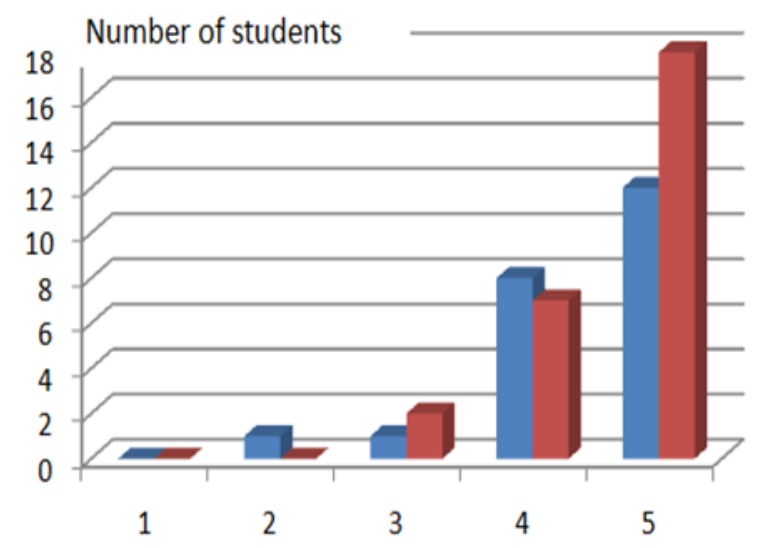

Figure 4. Distribution of answers to question 5, blue classic (academic year 2017-2018), red-flexible work schedule (academic year 2018-2019)

The average of the answers was 4.41 in 2018 and 4.43 in 2019 , and the majority of students consider that with the flexible work schedule the professional results and the grades obtained were better.

6. Participating in professional events will be a valuable experience.

6. Participating in professional events was a valuable experience.
Distribution of answers is given in Figure 5, blue classic, red flexible schedule

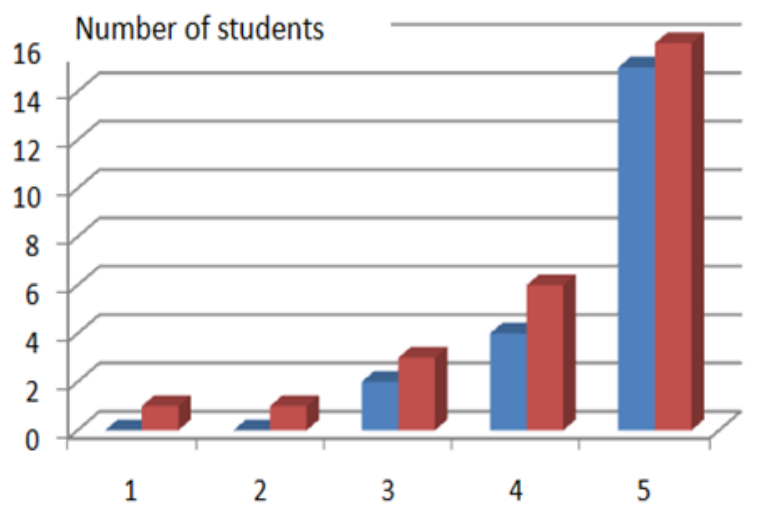

Figure 5. Distribution of answers to question 6, blue classic (academic year 2017-2018), red-flexible work schedule (academic year 2018-2019)

The averages of answers were 4.62 in 2018 and 4.14 in 2019. Unlike previous questions in which the perception of students who performed the activity flexibly was better than predicted, with this question students consider to a lesser extent that participation in professional events was valuable.

The difference in perception of the students from the two academic years can be represented graphically as the difference of the averages of the answers to the 6 questions, the average of the answers of those who carried out the flexible activity minus the average of the answers of those who carried out the classical activity, Figure 6.

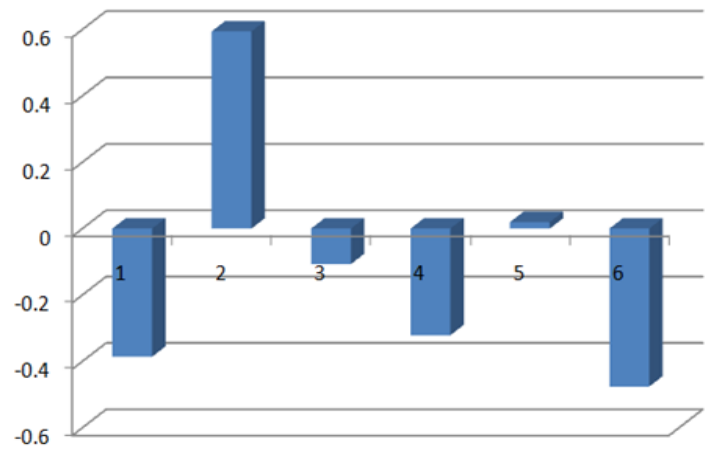

Figure 6. The difference in students' perception to the 6 questions

The difference in perception for the 6 questions calculated as a percentage is given in Table 1 .

Table 1.Difference in perception for the 6 questions

\begin{tabular}{|c|c|}
\hline Question & $\begin{array}{c}\text { Percentage } \\
\text { difference }\end{array}$ \\
\hline 1 & -7.72727 \\
\hline 2 & 11.88312 \\
\hline 3 & -2.14286 \\
\hline 4 & -6.42857 \\
\hline 5 & 0.38961 \\
\hline 6 & -9.52381 \\
\hline
\end{tabular}


It can be seen that the main positive perception appears at question 2, time management is being the highest gain noticed by students. At the opposite end, the main negative perception emerges with question 6 , which is the importance of participating in scientific events.

In terms of academic performances obtained by the students were taken into account the grade granted for the subject of preparing the diploma project, the participation in student scientific conferences (P1) and the presentation of the projects in front of the company representatives ( $\mathrm{P} 2)$. The comparison in table 2 shows the results from the academic years 2016-2017, 2017-2018 (classic schedule) and 20182019 (flexible schedule). The number of students varied in these years, so for a better relevance the table also provides percentages.

Table 2. Grades and student participation

\begin{tabular}{|c|c|c|c|}
\hline $\begin{array}{c}\text { Academic } \\
\text { year }\end{array}$ & $\begin{array}{c}2016-2017 \\
\text { (classic) }\end{array}$ & $\begin{array}{c}2017-2018 \\
\text { (classic) }\end{array}$ & $\begin{array}{c}2018-2019 \\
\text { (flexible) }\end{array}$ \\
\hline $\begin{array}{c}\text { Total } \\
\text { number of } \\
\text { students }\end{array}$ & 25 & 26 & 34 \\
\hline $\begin{array}{c}\text { Average } \\
\text { grades }\end{array}$ & 6.12 & 6.26 & 7.32 \\
\hline $\mathrm{P} 1$ & 12 & 9 & 15 \\
\hline $\mathrm{P} 2$ & 7 & 9 & 15 \\
\hline $\mathrm{P} 1(\%)$ & $48 \%$ & $34 \%$ & $44 \%$ \\
\hline $\mathrm{P} 2(\%)$ & $28 \%$ & $34 \%$ & $44 \%$ \\
\hline $\mathrm{P} 1+\mathrm{P} 2(\%)$ & $76 \%$ & $68 \%$ & $88 \%$ \\
\hline
\end{tabular}

From Table 2 it can be seen that in the academic year 2018-2019, both the average grades and participation in conferences were slightly better.

\section{Conclusion}

Some of the opinions of the students who carried out the activity flexibly were mentioned in the questionnaire. Following aspects were identified as advantages of the proposed work schedule: "1. We can manage time so that we can focus on a certain activity. 2. Mainly working students can manage their time much easier, having time for preparing the diploma project. 3 . The possibility to move class attendance, flexible schedule, catch up missed coursework, excellent way of working. 4. Possibility of completing the assessment tests more rapidly. 5 .
Given the opportunity that in in the fourth year all work for the diploma project, this program offered great advantage both for time management and writing the diploma thesis. 6 . I was more relaxed in terms of the project deadline. 7. Very good way of working because we can build a career during faculty, because besides studying we can work elsewhere as well. 8. Better time management, I managed to develop the project and documentation on time. 9. We can manage our time according to our personal schedule and we can ask teachers several questions."

The main advantage identified by the students was better time management. Some students are employed in the 4th academic year and according to them flexible scheduling is essential. Some students believe that flexible scheduling allows greater efficiency in preparing the diploma thesis. According to Table 1, academic performance of the students in flexible scheduling was better, so the students' perception was correct.

Some of the disadvantages of the flexible schedule mentioned by the students and written on the questionnaire were: "1. There is confusion about the number of attendances. 2. Individual work on the project is disrupted by the collective."

The advantages of the flexible schedule are obvious; they were confirmed by the academic results, the answers to an anonymous questionnaire and the observations of the students in the questionnaire. These benefits are felt especially by the working students during the fourth academic. However, the questionnaires raised some questions. First, the grading of students by several teachers and the management of absences produced errors and misunderstandings. This disadvantage can be eliminated by applying the Blockchain technology. To this end, a group of computer science enthusiast students began to develop simple software based on the Blockchain principles that are being currently worked on. A second important disadvantage is that individual work in the presence of other students involves the risk of mutual disturbance. During the next school year (2019-2020), teachers applied a more rigorous policy of maintaining a peaceful work atmosphere.

Unfortunately, the pandemic caused by COVID-19 virus forced the transition from face-to-face education to e-learning in mid-March 2020 and the experiment was postponed. 


\section{References}

[1]. Turkanović, M., Hölbl, M., Košič, K., Heričko, M., \& Kamišalić, A. (2018). EduCTX: A blockchain-based higher education credit platform. IEEE access, 6 , 5112-5127.

[2]. Casino, F., Dasaklis, T. K., \& Patsakis, C. (2019). A systematic literature review of blockchain-based applications: current status, classification and open issues. Telematics and Informatics, 36, 55-81.

[3]. Bambara, J. J., Allen, P. R., Iyer, K., Madsen, R., Lederer, S., \& Wuehler, M. (2018). Blockchain: A practical guide to developing business, law, and technology solutions. McGraw Hill Professional.

[4]. Lakhani, K. R., \& Iansiti, M. (2017). The truth about blockchain. Harvard Business Review, 95(1), 119127.

[5]. Hofmann, E., Strewe, U. M., \& Bosia, N. (2017). Supply chain finance and blockchain technology: the case of reverse securitisation. Springer.

[6]. Al Harthy, K., Al Shuhaimi, F., \& Al Ismaily, K. K. J. (2019, January). The upcoming Blockchain adoption in Higher-education: requirements and process. In 2019 4th MEC International Conference on Big Data and Smart City (ICBDSC) (pp. 1-5). IEEE.

[7]. Gräther, W., Kolvenbach, S., Ruland, R., Schütte, J., Torres, C., \& Wendland, F. (2018). Blockchain for education: lifelong learning passport. In Proceedings of 1st ERCIM Blockchain Workshop 2018. European Society for Socially Embedded Technologies (EUSSET).
[8]. Gong, X., Liu, X., Jing, S., Xiong, G., \& Zhou, J. (2018). Parallel-education-blockchain driven smart education: Challenges and issues. In 2018 Chinese Automation Congress (CAC) (pp. 2390-2395). IEEE.

[9]. Williams, P. (2019). Does competency-based education with blockchain signal a new mission for universities?. Journal of higher education policy and management, 41(1), 104-117.

[10]. Grech, A., \& Camilleri, A. F. (2017). Blockchain in Education. JRC Science for Policy Report, European Commission.

[11]. Collis, B., \& Moonen, J. (2012). Flexible Learning in a Digital World: Experiences and Expectations.

[12]. Barnett, R. (2014). Conditions of Flexibility: Securing a More Responsive Higher Education System. Higher Education Academy.

[13]. Rustin, M. (2003). Flexibility in higher education. In Towards a Post-Fordist Welfare State? (pp. 185210). Routledge.

[14]. Evans, C., Gbadamosi, G., \& Richardson, M. (2014). Flexibility, compromise and opportunity: Students' perceptions of balancing part-time work with a fulltime business degree. The International Journal of Management Education, 12(2), 80-90.

[15]. Burke, P. J., Bennett, A., Bunn, M., Stevenson, J., \& Clegg, S. (2017). It's About Time: working towards more equitable understandings of the impact of time for students in higher education. Project Report. Australia, Curtin University.

[16]. Reay, D., Crozier, G., \& Clayton, J. (2010). 'Fitting in'or 'standing out': Working-class students in UK higher education. British educational research journal, 36(1), 107-124. 